\title{
Ambulatory blood pressure response to a bout of HIIT in metabolic syndrome patients
}

Ramirez-Jimenez $\mathrm{M}^{1}$, Morales-Palomo $\mathrm{F}^{1}$, Pallares $\mathrm{JG}^{2}$ and Mora-Rodriguez $\mathrm{R}^{1}$, Ortega $\mathrm{JF}^{1}$.

${ }^{1}$ Exercise Physiology Lab at Toledo, University of Castilla-La Mancha, Spain.

${ }^{2}$ Human Performance and Sport Science Lab, University of Murcia, Spain.

\section{Corresponding author:}

Ricardo Mora-Rodriguez. Exercise Physiology Lab at Toledo

University of Castilla-La Mancha, 45071 Toledo, Spain

Phone $34+925268800$

Email: ricardo.mora@uclm.es

Short title: Hypertension in metabolic syndrome

\section{Acknowledgements}

This work was partially funded by a grant from the Spanish Ministry of Economy and Competivity (DEP-2014-52930-R). There is no conflict of interest. 


\section{ABSTRACT}

Purpose: The effectiveness of exercise to lower blood pressure may depend on the type and intensity of exercise. We study the short-term (i.e., 14-hour) effects of a bout of high-intensity aerobic interval training (HIIT) on blood pressure in metabolic syndrome (MSyn) patients. Methods: Nineteen MSyn patients ( $55.2 \pm 7.3$ years, 6 women) entered the study. Eight of them were normotensive and eleven hypertensive according to MSyn threshold ( $\geq 130 \mathrm{mmHg}$ for SBP and/or $\geq 85 \mathrm{mmHg}$ for DBP). In the morning of three separated days, they underwent a cycling exercise bout of HIIT ( $>90 \%$ of maximal heart rate, $\sim 85 \% \mathrm{VO}_{2 \max }$ ), or a bout of isocaloric moderate intensity continuous training (MICT; $~ 70 \%$ of maximal heart rate, $\sim 60 \% \mathrm{VO}_{2 \max }$ ) or a control no-exercise trial (REST). After exercise, ambulatory blood pressure (ABP; 14-hour) was monitored while subjects continued their habitual daily activities wearing a wrist-band activity monitor. Results: No ABP differences were found for normotensive subjects. In hypertensive subjects, systolic ABP was reduced by $6.1 \pm 2.2 \mathrm{mmHg}$ after HIIT compared to MICT and REST (130.8 \pm 3.9 vs $137.4 \pm 5.1$ and $136.4 \pm 3.8 \mathrm{mmHg}$, respectively $\mathrm{p}<0.05)$. However, diastolic ABP was similar in all three trials (77.2 \pm 2.6 vs $78.0 \pm 2.6$ and $78.9 \pm 2.8 \mathrm{mmHg}$, respectively). Motion analysis revealed no differences among trials during the 14-hour. Conclusion: This study suggests that the blood pressure reducing effect of a bout of exercise is influence by the intensity of exercise. A HIIT exercise bout is superior to an equivalent bout of continuous exercise when used as a non-pharmacological aid in the treatment of hypertension in MSyn.

Keywords: Hypertension; metabolic syndrome; motion analysis; ambulatory blood pressure. 


\section{List of abbreviations}

$\mathrm{ABP}$ Ambulatory blood pressure.

BMI ------------------- Body mass index.

DBP ------------------- Diastolic blood pressure.

GXT ------------------- Graded exercise testing.

HIIT ------------------- High-intensity aerobic interval training.

HSD -------------------- Honest significant difference.

MICT ------------ Moderate intensity continuous training.

MSyn ------------------- Metabolic syndrome.

PEH -------------------- Post-exercise hypotension.

SBP ------------- Systolic blood pressure.

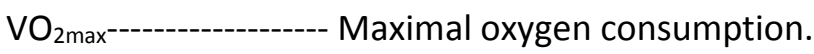




\section{INTRODUCTION}

Metabolic syndrome is cluster of conditions that raises the risk of suffering cardiovascular diseases among other health problems. Hypertension, one of the components of MSyn, increases the risk of developing heart failure, atrial fibrillation (Angeli et al. 2014), stroke, coronary artery disease (Shen et al. 2013) and peripheral vascular diseases. Hypertension is not only one of the components of metabolic syndrome, but is the component more prevalent $(90 \%)$ in subjects with metabolic syndrome in south Europe (Scuteri et al. 2015). The remaining MSyn components, increased waist circumference, dyslipidemia and impaired fasting glucose also increase the risk of cardiovascular diseases. Some of these factors interact to raise the risk of suffering cardiovascular diseases. For instance, overweight and abdominal obesity, raise the prevalence of hypertension (Stamler et al. 1978) and thus the risk of suffering cardiovascular diseases (DeVallance et al. 2015). On the other hand, aerobic exercise training, a non-pharmacological intervention, reduces resting blood pressure (Seals and Hagberg 1984) even in people with resistant hypertension (Dimeo et al. 2012).

High intensity interval training (HIIT) is a training method previously reserved to improve athletic performance that has been incorporated into exercise health promotion programs for being less time-consuming than moderate intensity continuous training (MICT) while producing similar metabolic health benefits such as, increased mitochondria biogenesis and insulin sensitivity (Maclnnis and Gibala 2016)). It is also well established that even in patients with cardiometabolic diseases, HIIT improves cardiorespiratory fitness (i.e., $\mathrm{VO}_{2 \max }$ ) more efficiently than when using MICT (Stensvold et al. 2010; Weston et al. 2014). A recent meta-analysis sustains that HIIT is also superior at improving vascular function when compared to MICT, a finding probably linked to the larger improvement in $\mathrm{VO}_{2 \max }$ and other cardiovascular risk factors (Ramos et al. 2015). Furthermore, the training studies using HIIT on hypertensive or MSyn patients report a positive effect on reducing resting blood pressure (Molmen-Hansen et al. 2012; Mora-Rodriguez et al. 2014; Tjonna et al. 2008) apparently by increasing vessel vasodilation (Tjonna et al. 2008) and reducing arterial stiffness 
(Donley et al. 2014). On the other hand, MICT has unique positive effects on increasing resting

artery diameter not obtained by training using HIIT (Sawyer et al. 2016).

The chronic effects of training on lowering blood pressure are likely due to the summation of the acute effect of each exercise bout in this physiological response. The acute effect of exercise on blood pressure is termed post-exercise hypotension (PEH) and has been the topic of numerous publications. The initial studies sustained that exercise intensity did not affect the magnitude or duration of PEH (MacDonald et al. 1999; Pescatello et al. 1991). Most of these studies examined the effects of exercise at moderate-intensities (i.e., below $80 \%$ of maximal heart rate; (Cornelissen et al. 2009; Pescatello et al. 2004a; Pescatello et al. 2004b). We have recently published that a bout of HIIT is more effective at lowering blood pressure in hypertensive MSyn patients than an isocaloric bout of MICT (Morales-Palomo et al. 2017) when blood pressure effects were monitored during the 60 min that followed the exercise bout. However, we have not determined if this superior blood pressure lowering effects of HIIT last during the hours of habitual daily activity that follow exercise. This is important to be determined since a reduction in hypertensive peaks during the would have a direct clinical application. There are several studies that have attempted to examine the longer time course of PEH using ambulatory blood pressure monitoring (ABM).

These studies are particular interesting because ABM does not restrict subjects from their routine daily activities. Thus, the effects of exercise or training can be studied during the out-of-the laboratory real life situation. The purpose of this study was to determine if a single bout of HIIT has a longer lasting effect on lowering blood pressure than an isocaloric bout of MICT using ABM to follow the BP response during 14 hours after exercise. We hypothesized that HIIT will result in larger PEH than MICT not only immediately after exercise but also during the daily activities that follow morning exercise. 
METHODS

Participants. Nineteen subjects ( $55.2 \pm 7.3$ years) with a BMI of $30 \pm 4 \mathrm{~kg} \cdot \mathrm{m}^{-2}$ (Table 1$)$ and diagnosed with metabolic syndrome (Alberti et al. 2009) were recruited for this study. All subjects provided written, witnessed, informed consent of the protocol approved by the local Hospital's Ethics Committee in accordance with the world medical association Declaration of Helsinki.

Preliminary testing. Peak aerobic capacity $\left(\mathrm{VO}_{2 \mathrm{PEAK}}\right)$ was assessed on an electronically-braked cycle ergometer (Ergoselect 200, Ergoline, Germany) during graded exercise testing (GXT) using indirect calorimetry (Quark b², Cosmed, Italy) with 12-lead ECG monitoring (Quark T12, Cosmed, Italy). The highest heart rate value obtained during the test was considered HR $R_{\text {PEAK. }}$.

Blood pressure screening. On preliminary testing day, three consecutive blood pressure measurements were taken every 5 minutes after fifteen minutes in supine resting. Measures were taken in the non-dominant arm, since that arm was also used for ambulatory blood pressure monitoring. The mean of these three measurements determined which subjects had hypertension according to the metabolic syndrome criteria (systolic blood pressure $\geq 130$ and/or diastolic blood pressure $\geq 85 \mathrm{mmHg}$; (Alberti et al. 2009)). Based on this preliminary test, two groups were established, a normotensive group $(n=8)$ with average SBP/DBP of $116 / 65 \mathrm{mmHg}$ and a hypertensive group $(n=11)$ with an average SBP/DBP of $135 / 86 \mathrm{mmHg}$.

Experimental design. Using a repeated measures crossover randomized design subjects completed three trials, separated by at least three days in a randomized order. In one occasion subjects completed a bout of high intensity interval training (HIIT) consisting on 10-min warm-up followed by $4 \times 4$-min intervals at $90 \%$ of HREAK interspersed with 3-min active recovery at $70 \%$ HREAK and a 5-min warm down for a total of 43 min of exercise. In another occasion, they underwent a bout of moderately-intense continuous exercise training (MICT) with a duration of $53 \pm 5$ min at $60 \%$ of HREAK. In a third trial subjects arrived to the laboratory at the same time of day than in the other two trials and they remained seated during 50 min (REST). Exercise duration for MICT was calculated to match HIIT trial for energy expenditure. Subjects maintained a similar pedaling 
cadence in both exercise trials (70-80 rpm). During exercise, HR was monitored every $5 \mathrm{~s}$ (Accurex coded; Polar, Kempele, Finland) by a researcher and workload adjusted to reach the desired target HR.

Experimental protocol. Trials were conducted at least $72 \mathrm{~h}$ after the last training bout. Subjects were instructed to refrain, during the 24-hours prior to the trials, from consumption of any stimulant that could altered their cardiovascular response to exercise (alcohol, tobacco, coffee, tea, or herbal extracts). All trials were conducted between 7:00-9:00 hours AM. One hour before arrival to the laboratory, subjects ingested a light breakfast $(330 \mathrm{~mL}$ fruit milkshake and a pastry for a total of $624 \mathrm{kcal}$ and $68 \mathrm{~g}$ of carbohydrate). An euhydrated state was maintained through ad libitum water consumption during the trials.

Ambulatory blood pressure measurement. An ambulatory blood pressure device (Oscar2, Suntech, Morrisville, NC) based on oscillometry with step deflation was used to measure the diurnal 14-h ambulatory blood pressure and heart rate in all subjects. The cuff was attached to the nondominant arm and an adequate size cuff was assigned to each subject depending on their arm circumference. The ABP device was programmed to take a measurement every 20 minutes from 9:00 AM to 23:00 PM. If the first measurement was unsuccessful one repeat measurement was taken immediately after. The inflation of the bladder cuff for each measurement was $30 \mathrm{mmHg}$ greater than the previous systolic reading. Subjects were instructed: a) to relax arm and maintain elbow extension during the blood pressure measurement, b) to not remove the cuff and the ambulatory blood pressure device until 23:00 PM, c) to abstain from vigorous exercise but do not abstain from physical activity of their daily routine.

Physical posture/activity control. After exercise (or rest in the REST trial) subjects were provided with a wrist worn activity monitor that uses a triaxial accelerometry technology (Polar Electro, Kempele, Finland). This device estimated energy expenditure and monitors the time spent in three different body positions; resting (i.e., sitting and lying down), standing and walking, during the 14-h of ambulatory pressure measurements. Wristbands were placed in the non-dominant arm. 
Ambulatory blood pressure data. After each measurement, data were downloaded to the

computer using AccuWin Pro v3.4 software. Data was then manually reviewed to detect missing and erroneous measurements. Individual measurements were removed if: a) systolic blood pressure was $>240 \mathrm{mmHg}$ or $<50 \mathrm{mmHg}$ or diastolic blood pressure $>140 \mathrm{mmHg}$ or $<40 \mathrm{mmHg}$; b) heart rate was $>150 \mathrm{bpm}$ or $<40 \mathrm{bpm}$; c) systolic and diastolic blood pressure deviated \pm 50 and $\pm 20 \mathrm{mmHg}$ respectively in comparison with immediately previous and later value; d) heart rate deviated \pm 30 bpm from previous or later value in accordance with Padilla et al., (Padilla et al. 2005).

Statistical analysis. Data in figures is presented as mean \pm standard error of the mean (SEM). Descriptive statistics (mean \pm standard deviation) were used for subject's characteristics (Table 1). Independent t-test was performed to compare the initial blood pressure, heart rate and anthropometric data between the groups. Data collected overtime (ABP, HR and motion analysis) in the three trials was analyzed using one-way (treatment) repeated measures ANOVA. After a significant $F$ test, pairwise differences were identified using post hoc Tukey's HSD. Statistical significance level was set at $P \leq 0.05$. 


\section{RESULTS}

Table 1 shows that subjects in each group were similar in age, body composition and cardiorespiratory fitness level (i.e., $\mathrm{VO}_{2 \text { peak }}$ ) and only differed in their resting blood pressure.

Ambulatory blood pressure responses. Collected blood pressure and heart rate readings were averaged hourly. Averaged systolic blood pressure during the 14-hour of ABP collection did not differ among trials in the normotensive group (i.e., $123.6 \pm 4.4$ vs. $127.1 \pm 4.9$ vs. $122.5 \pm 4.4 \mathrm{mmHg}$, for HIIT, MCIT and REST, respectively). However, in the hypertensive group, systolic ABP was lower after HIIT than MCIT and REST (130.8 \pm 3.9 vs $137.4 \pm 5.1$ and $136.4 \pm 3.8 \mathrm{mmHg}$, respectively $p<0.05$; Figure 1). Diastolic blood pressure was not affected by either exercise type or rest in normotensive subjects (i.e., $70.9 \pm 3.0$ vs. $72.1 \pm 3.1$ vs. $69.6 \pm 1.9 \mathrm{mmHg}$, for HIIT, MCIT and REST, respectively). In the hypertensive group, there were no differences either in diastolic blood pressure among trials (i.e., $77.2 \pm 2.6$ vs. $78.0 \pm 2.6$ vs. $78.9 \pm 2.8 \mathrm{mmHg}$, for HIIT, MCIT and REST, respectively; Figure 2 ). When mean arterial pressure was calculated, the results followed the pattern of systolic blood pressure. In the normotensive group, there were no differences among trials (i.e., $88.5 \pm 4.4$ vs. $90.5 \pm 4.9$ vs. 87.3 $\pm 4.4 \mathrm{mmHg}$, for HIIT, MCIT and REST, respectively), while HIIT resulted in lower average systolic ABP than the other two trials $(95.1 \pm 3.9$ vs $97.8 \pm 5.1$ and $98.1 \pm 3.8 \mathrm{mmHg}$, respectively $p<0.05)$.

Heart rate response. Although during the first hours of data collection there was a tendency for heart rate to be elevated after HIIT and MCIT trials in comparison to REST as average during the 14 hours of data collection (Figure 3 ) there was no different among trials in the normotensive group (i.e., $77.1 \pm 5.6$ vs. $80.1 \pm 6.1$ vs. $72.8 \pm 5.0$ beats $\cdot \mathrm{min}^{-1}$, for HIIT, MCIT and REST, respectively) or the hypertensive group (i.e., $80.5 \pm 4.5$ vs. $76.6 \pm 3.9$ vs. $76.1 \pm 4.0$ beats $\cdot \mathrm{min}^{-1}$, for HIIT, MCIT and REST, respectively).

Body motion and position. Physical activity distributed in three body motion modes; resting, standing and walking is displayed in Figure 4 for both groups. There were no statistically differences across trials within each group of subjects $(P>0.05)$. 
1

2

3

4

5

9

10

11

12

13

14

15

16

17

18

19

20

21

22

23

24

25

26

27

28

29

30

31

32

33

34

35

36

37

38

39

40

41

42

43

44

45

46

47

48

49

50

51

52

53

54

55

56

57

58

59

60

61

62

63

64

65 


\section{DISCUSSION}

We aimed to measure the long-term (14-hour) post-exercise blood pressure lowering effects of a bout of intense interval exercise in hypertense and normotense metabolic syndrome patients. We used ambulatory blood pressure (ABP) monitoring while subjects continue with their routine daily activities after the morning bout of exercise. The results were that only in hypertensive subjects and only after the most intense type of exercise (i.e. high intensity exercise training; HIIT) systolic ABP was significantly reduced by $6.1 \pm 2.2 \mathrm{mmHg}(p<0.05)$. This reduction did not take place after the bout of isocaloric moderately-intense continuous training (MICT). This suggests that exercise intensity, but not exercise caloric expenditure, determines the magnitude of reduction in $A B P$ after exercise (Figure 1). The finding that only hypertensive subjects benefited from exercise is in agreement with that data from other studies (Padilla et al. 2005). Pescatello and colleagues (Pescatello et al. 2004a) suggest baseline blood pressure as a predictor of post-exercise hypotension (i.e., the higher the baseline blood pressure the larger the lowering effect of exercise). This may be due to a floor effect where a physiological variable cannot be reduced below its homeostatic clinical level (i.e., 120/80 mmHg for systolic and diastolic blood pressure in a young person) without inducing responses to prevent hypotension.

It was initially thought that the magnitude of the post-exercise hypotension was not related with the intensity, duration or type of exercise (MacDonald 2002). Still the general recommendation for the treatment of hypertension with exercise are to perform aerobic, moderate-intensity (40-70\% $\mathrm{VO}_{2 \max }$ ) prolonged exercise (i.e., 20-60 min per session; (Pescatello et al. 2004a)). However, this view has recently changed upon the appearance of studies showing that vigorous exercise results in larger post-exercise hypotension than a bout of moderate aerobic exercise (Eicher et al. 2010). Furthermore, other studies show that the post-exercise hypotension is maintained longer after more intense exercise (Angadi et al. 2015; Keese et al. 2012). The studies that started to show larger postexercise hypotension with intense exercise used graded exercise stress test (GXT; (Cleroux et al. 1991; Piepoli et al. 1994)). GXT requires participants exercising to the point of volitional fatigue 
which results in marked elevations in BP, heart rate, cardiac output, high muscle metabolite and heat accumulation. Those are responses that we recently reported to be increased during of HIIT in comparison to MICT in metabolic syndrome patients (Morales-Palomo et al. 2016). Thus, probably some of those factors were involved in the superior blood pressure response after HIIT although our study does not allow identification of the mechanisms.

HIIT but not MICT had a significant blood pressure reducing effect in hypertensive subjects. The differential aspects of HIIT vs MICT were higher exercise intensity ( $90 \%$ of HRPEAK $)$ and intensity alternation. It is unclear how those factors may have produced larger hypotension. Possible factors behind the larger magnitude of post-exercise hypotension after HIIT include decreased vascular resistance to flow in skeletal muscle, lingering from the previous exercise bout. Recent data suggest that increased temperature and reductions in blood volume are associated to the early reductions in blood pressure but not to the prolonged effects (Lynn et al. 2009; Wilkins et al. 2004). Blood concentrations of potential vasodilators (adrenaline, adenosine, potassium, atrial natriuretic peptide, nitric oxyde) and vasoconstriction agents (renin, angiotensin II, antidiuretic hormone) do not change in agreement with post-exercise hypotension (MacDonald 2002) although any of these substances may be responsible for alterations in vascular sensitivity and thus post-exercise hypotension. For instance, Halliwill and co-workers argue that histaminergic receptors are involved in the post-exercise hypotension (Halliwill et al. 2013), but the role of this receptors in the sustained hypotension is unclear. Another possibility for the sustained post-exercise hypotension is a reduced sympathetic efferent activity with decrease in vasoconstriction in comparison to pre-exercise. Our findings of no difference in heart rate between trials (indirect marker of sympathetic nerve activity; Figure 3) suggests that sympathetic nerve activity was not decreased during the period over which the hypotension occurred.

Blood pressure like many other physiological variables is affected by circadian rhythm (Giles 2006). For instance, it has been reported that post-exercise hypotension is greater after exercise in the afternoon (16:00 hours) compared with exercise in the morning (8:00 hours) likely because 
blood pressure is elevated at this time (Jones et al. 2008)). In contrast, we observe a clear reduction

in blood pressure at 16 hours while Jones et al.,(Jones et al. 2008) find that in the afternoon blood pressure is higher than at $8 \mathrm{am}$. It is important to note, that our subjects are from a south Mediterranean country and lunch (which is the highest caloric meal) occurs around 14-15 hours. Thus, the decrease in blood pressure at 16 hours may correspond to the digestive requirements of that large meal. It is possible that HIIT before the meal could have promoted the effects of digestion on vasodilating the splanchnic or other vascular beds accounting for the reduction in systolic blood pressure. It is unclear if HIIT resulted in lower systolic blood pressure than MICT during those digestion hours. However, HIIT results in higher elevations in blood lactate than MICT (MoralesPalomo et al. 2016) which clearance involves the splanchnic circulation.

One study stands alone on reporting the post-exercise hypotension in MSyn patients (Pescatello et al. 2008). They found that in the MSyn group the post-exercise hypotension response was much attenuated in comparison to overweight, middle-aged, hypertensive counterparts with similarly low cardiovascular fitness level. They reasoned that MSyn impaired insulin actions of MSyn may also reflect in a blunted insulin vasodilating effect. It is also possible that the exercise intensities that they used in the study $\left(40-60 \% \mathrm{VO}_{2 \text { peak }}\right)$ were not enough stimulus to lower blood pressure. In agreement with their data, 53 min of pedaling at $60 \%$ of $\mathrm{HR}_{\text {MAX }}$ (i.e., MICT trial) did not lower blood pressure in our MSyn subjects.

The ABM technique has some limitations important to mention. Physical activity, body position, breathing cycle, and circadian rhythm all influence blood pressure. The influence of breathing cycle and circadian rhythm were normalized by conducting a control trial with identical measurement protocol but lacking exercise. However, it is plausible that differences in daily physical activity and body position may have occurred among trials. It could be hypothesized that most fatiguing exercise would induce a more sedentary period post-exercise under our free-living conditions, explaining the reductions in blood pressure after HIIT. This seems to be the case in people that are not used to physical activity (Kriemler et al. 1999). To investigate if we have incurred 
in that bias we monitored daily physical activity using activity wristbands and could not find differences among trials (Figure 4). We did not measure asleep blood pressure to avoid disrupting the sleep and rest of the subjects. However, this may be view as a limitation of our study since data in a large sample reveals that sleep systolic blood pressure is the only ABP parameter that predicts of cardiovascular morbidity and mortality (Hermida et al. 2011). Finally, the subjects were tested while maintaining their medications to simulate a real-world scenario. However, it is unclear if exercise combined with antihypertensive medication may result in a synergistic effect on blood pressure reduction.

In summary, our study suggests that the long term (i.e., 14 hours) blood pressure reducing effect of a bout of exercise depends on the intensity and type of exercise. A bout of high-intensity interval training is superior to an isocaloric bout of continuous exercise on reducing blood pressure control in hypertensive subject during the day. Thus, our data suggest that HIIT exercise may serve as a non-pharmacological aid in the treatment of the hypertension associated to metabolic syndrome.

\section{Acknowledgements}

This work was partially funded by a grant from the Spanish Ministry of Economy and Competivity (DEP-2014-52930-R). There is no conflict of interest. 


\section{REFERENCES}

Alberti KG, Eckel RH, Grundy SM, Zimmet PZ, Cleeman JI, Donato KA, Fruchart JC, James WP, Loria CM, Smith SC, Jr., International Diabetes Federation Task Force on E, Prevention, Hational Heart L, Blood I, American Heart A, World Heart F, International Atherosclerosis S, International Association for the Study of O (2009) Harmonizing the metabolic syndrome: a joint interim statement of the International Diabetes Federation Task Force on Epidemiology and Prevention; National Heart, Lung, and Blood Institute; American Heart Association; World Heart Federation; International Atherosclerosis Society; and International Association for the Study of Obesity. Circulation 120 (16):1640-1645. doi:10.1161/CIRCULATIONAHA.109.192644

Angadi SS, Bhammar DM, Gaesser GA (2015) Postexercise Hypotension After Continuous, Aerobic Interval, and Sprint Interval Exercise. J Strength Cond Res 29 (10):2888-2893. doi:10.1519/JSC.0000000000000939

Angeli F, Reboldi G, Verdecchia P (2014) Hypertension, inflammation and atrial fibrillation. J Hypertens 32 (3):480-483. doi:10.1097/HJH.0000000000000112

Cleroux J, Kouame N, Nadeau A, Lacourciere Y (1991) Forearm hemodynamics during recovery from exercise in hypertensive and normotensive subjects. J Hypertens Suppl 9 (6):S124-125

Cornelissen VA, Arnout J, Holvoet P, Fagard RH (2009) Influence of exercise at lower and higher intensity on blood pressure and cardiovascular risk factors at older age. J Hypertens 27 (4):753-762. doi:10.1097/HJH.0b013e328322cf60

DeVallance E, Fournier SB, Donley DA, Bonner DE, Lee K, Frisbee JC, Chantler PD (2015) Is obesity predictive of cardiovascular dysfunction independent of cardiovascular risk factors? Int J Obes (Lond) 39 (2):244-253. doi:10.1038/ijo.2014.111

Dimeo F, Pagonas N, Seibert F, Arndt R, Zidek W, Westhoff TH (2012) Aerobic exercise reduces blood pressure in resistant hypertension. Hypertension 60 (3):653-658.

doi:10.1161/HYPERTENSIONAHA.112.197780

Donley DA, Fournier SB, Reger BL, DeVallance E, Bonner DE, Olfert IM, Frisbee JC, Chantler PD (2014) Aerobic exercise training reduces arterial stiffness in metabolic syndrome. J Appl Physiol (1985) 116 (11):1396-1404. doi:10.1152/japplphysiol.00151.2014

Eicher JD, Maresh CM, Tsongalis GJ, Thompson PD, Pescatello LS (2010) The additive blood pressure lowering effects of exercise intensity on post-exercise hypotension. Am Heart J 160 (3):513-520. doi:10.1016/j.ahj.2010.06.005

Giles TD (2006) Circadian rhythm of blood pressure and the relation to cardiovascular events. J Hypertens Suppl 24 (2):S11-16. doi:10.1097/01.hjh.0000220098.12154.88

Halliwill JR, Buck TM, Lacewell AN, Romero SA (2013) Postexercise hypotension and sustained postexercise vasodilatation: what happens after we exercise? Exp Physiol 98 (1):7-18. doi:10.1113/expphysiol.2011.058065

Hermida RC, Ayala DE, Mojon A, Fernandez JR (2011) Decreasing sleep-time blood pressure determined by ambulatory monitoring reduces cardiovascular risk. J Am Coll Cardiol 58 (11):1165-1173. doi:10.1016/j.jacc.2011.04.043 
Jones H, Pritchard C, George K, Edwards B, Atkinson G (2008) The acute post-exercise response of blood pressure varies with time of day. Eur J Appl Physiol 104 (3):481-489. doi:10.1007/s00421-008-0797-4

Keese F, Farinatti P, Pescatello L, Cunha FA, Monteiro WD (2012) Aerobic exercise intensity influences hypotension following concurrent exercise sessions. Int J Sports Med 33 (2):148153. doi:10.1055/s-0031-1291321

Kriemler S, Hebestreit H, Mikami S, Bar-Or T, Ayub BV, Bar-Or O (1999) Impact of a single exercise bout on energy expenditure and spontaneous physical activity of obese boys. Pediatr Res 46 (1):40-44

Lynn BM, Minson CT, Halliwill JR (2009) Fluid replacement and heat stress during exercise alter post-exercise cardiac haemodynamics in endurance exercise-trained men. J Physiol 587 (Pt 14):3605-3617. doi:10.1113/jphysiol.2009.171199

MacDonald J, MacDougall J, Hogben C (1999) The effects of exercise intensity on post exercise hypotension. J Hum Hypertens 13 (8):527-531

MacDonald JR (2002) Potential causes, mechanisms, and implications of post exercise hypotension. J Hum Hypertens 16 (4):225-236. doi:10.1038/sj.jhh.1001377

Maclnnis MJ, Gibala MJ (2016) Physiological adaptations to interval training and the role of exercise intensity. J Physiol. doi:10.1113/JP273196

Molmen-Hansen HE, Stolen T, Tjonna AE, Aamot IL, Ekeberg IS, Tyldum GA, Wisloff U, Ingul CB, Stoylen A (2012) Aerobic interval training reduces blood pressure and improves myocardial function in hypertensive patients. Eur J Prev Cardiol 19 (2):151-160.

doi:10.1177/1741826711400512

Mora-Rodriguez R, Ortega JF, Hamouti N, Fernandez-Elias VE, Canete Garcia-Prieto J, Guadalupe-Grau A, Saborido A, Martin-Garcia M, Guio de Prada V, Ara I, Martinez-Vizcaino V (2014) Time-course effects of aerobic interval training and detraining in patients with metabolic syndrome. Nutr Metab Cardiovasc Dis 24 (7):792-798.

doi:10.1016/j.numecd.2014.01.011

Morales-Palomo F, Ramirez-Jimenez M, Ortega JF, Pallares JG, Mora-Rodriguez R (2016) Cardiovascular Drift during Training for Fitness in Metabolic Syndrome Patients. Med Sci Sports Exerc. doi:10.1249/MSS.0000000000001139

Morales-Palomo F, Ramirez-Jimenez M, Ortega JF, Pallares JG, Mora-Rodriguez R (2017) Acute hypotension after high-intensity interval exercise in metabolic syndrome patients. International Journal of Sports Medicine.

Padilla J, Wallace JP, Park S (2005) Accumulation of physical activity reduces blood pressure in pre- and hypertension. Med Sci Sports Exerc 37 (8):1264-1275

Pescatello LS, Blanchard BE, Van Heest JL, Maresh CM, Gordish-Dressman H, Thompson PD (2008) The metabolic syndrome and the immediate antihypertensive effects of aerobic exercise: a randomized control design. BMC Cardiovasc Disord 8:12. doi:10.1186/1471-2261-812 
Pescatello LS, Fargo AE, Leach CN, Jr., Scherzer HH (1991) Short-term effect of dynamic exercise on arterial blood pressure. Circulation 83 (5):1557-1561

Pescatello LS, Franklin BA, Fagard R, Farquhar WB, Kelley GA, Ray CA, American College of Sports M (2004a) American College of Sports Medicine position stand. Exercise and hypertension. Med Sci Sports Exerc 36 (3):533-553

Pescatello LS, Guidry MA, Blanchard BE, Kerr A, Taylor AL, Johnson AN, Maresh CM, Rodriguez $\mathrm{N}$, Thompson PD (2004b) Exercise intensity alters postexercise hypotension. J Hypertens 22 (10):1881-1888

Piepoli M, Isea JE, Pannarale G, Adamopoulos S, Sleight P, Coats AJ (1994) Load dependence of changes in forearm and peripheral vascular resistance after acute leg exercise in man. J Physiol 478 ( Pt 2):357-362

Ramos JS, Dalleck LC, Tjonna AE, Beetham KS, Coombes JS (2015) The impact of high-intensity interval training versus moderate-intensity continuous training on vascular function: a systematic review and meta-analysis. Sports Med 45 (5):679-692. doi:10.1007/s40279-0150321-z

Sawyer BJ, Tucker WJ, Bhammar DM, Ryder JR, Sweazea KL, Gaesser GA (2016) Effects of highintensity interval training and moderate-intensity continuous training on endothelial function and cardiometabolic risk markers in obese adults. J Appl Physiol (1985) 121 (1):279-288. doi:10.1152/japplphysiol.00024.2016

Scuteri A, Laurent S, Cucca F, Cockcroft J, Cunha PG, Manas LR, Mattace Raso FU, Muiesan ML, Ryliskyte L, Rietzschel E, Strait J, Vlachopoulos C, Volzke H, Lakatta EG, Nilsson PM, Metabolic S, Arteries Research C (2015) Metabolic syndrome across Europe: different clusters of risk factors. Eur J Prev Cardiol 22 (4):486-491. doi:10.1177/2047487314525529

Seals DR, Hagberg JM (1984) The effect of exercise training on human hypertension: a review. Med Sci Sports Exerc 16 (3):207-215

Shen L, Ma H, Xiang MX, Wang JA (2013) Meta-analysis of cohort studies of baseline prehypertension and risk of coronary heart disease. Am J Cardiol 112 (2):266-271. doi:10.1016/j.amjcard.2013.03.023

Stamler R, Stamler J, Riedlinger WF, Algera G, Roberts RH (1978) Weight and blood pressure. Findings in hypertension screening of 1 million Americans. JAMA 240 (15):1607-1610

Stensvold D, Tjonna AE, Skaug EA, Aspenes S, Stolen T, Wisloff U, Slordahl SA (2010) Strength training versus aerobic interval training to modify risk factors of metabolic syndrome. J Appl Physiol 108 (4):804-810. doi:00996.2009

Tjonna AE, Lee SJ, Rognmo O, Stolen TO, Bye A, Haram PM, Loennechen JP, Al-Share QY, Skogvoll E, Slordahl SA, Kemi OJ, Najjar SM, Wisloff U (2008) Aerobic interval training versus continuous moderate exercise as a treatment for the metabolic syndrome: a pilot study. Circulation 118 (4):346-354. doi:10.1161/circulationaha.108.772822

Weston KS, Wisloff U, Coombes JS (2014) High-intensity interval training in patients with lifestyle-induced cardiometabolic disease: a systematic review and meta-analysis. Br J Sports Med 48 (16):1227-1234. doi:10.1136/bjsports-2013-092576 
Wilkins BW, Minson CT, Halliwill JR (2004) Regional hemodynamics during postexercise hypotension. II. Cutaneous circulation. J Appl Physiol 97 (6):2071-2076.

doi:10.1152/japplphysiol.00466.2004 


\section{FIGURE CAPTIONS}

Figure 1. Systolic ambulatory blood pressure response during the 14 hours following a bout of high intensity interval exercise (HIIT), isocaloric continuous exercise (MICT) or no-exercise control trial (REST) in normotensive $(n=8)$ and hypertensive $(n=11)$ metabolic syndrome subjects. Data are means \pm SEM. * Area under the curve significantly different from REST trial $(P<0.05) .+$ Area under the curve significantly different from MICT trial.

Figure 2. Diastolic ambulatory blood pressure response during the 14 hours following a bout of exercise (HIIT and MICT) or no-exercise control trial (REST) in normotensive $(n=8)$ and hypertensive $(n=11)$ metabolic syndrome subjects. Data are means \pm SEM.

Figure 3. Heart rate response during the 14 hours following a bout of exercise (HIIT and MICT) or noexercise control trial (REST) in normotensive $(n=8)$ and hypertensive $(n=11)$ metabolic syndrome subjects. Data are means \pm SEM.

Figure 4. Body motion/position analysis during the 14 hours following a bout of exercise (HIIT and MICT) or no-exercise control trial (REST) in normotensive $(n=8)$ and hypertensive $(n=11)$ metabolic syndrome subjects. Data are means \pm SEM. 
Figure 1
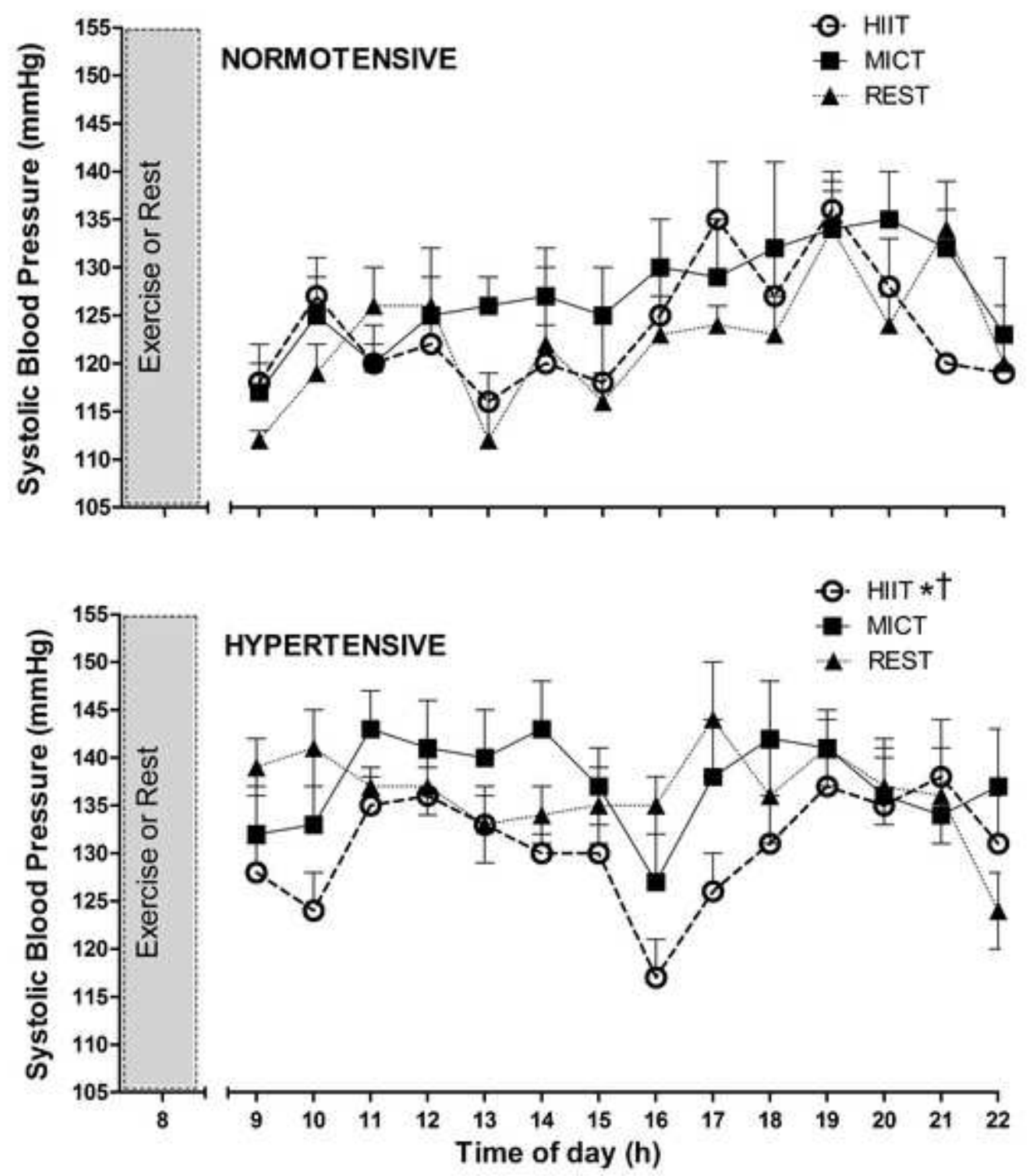
Figure 2
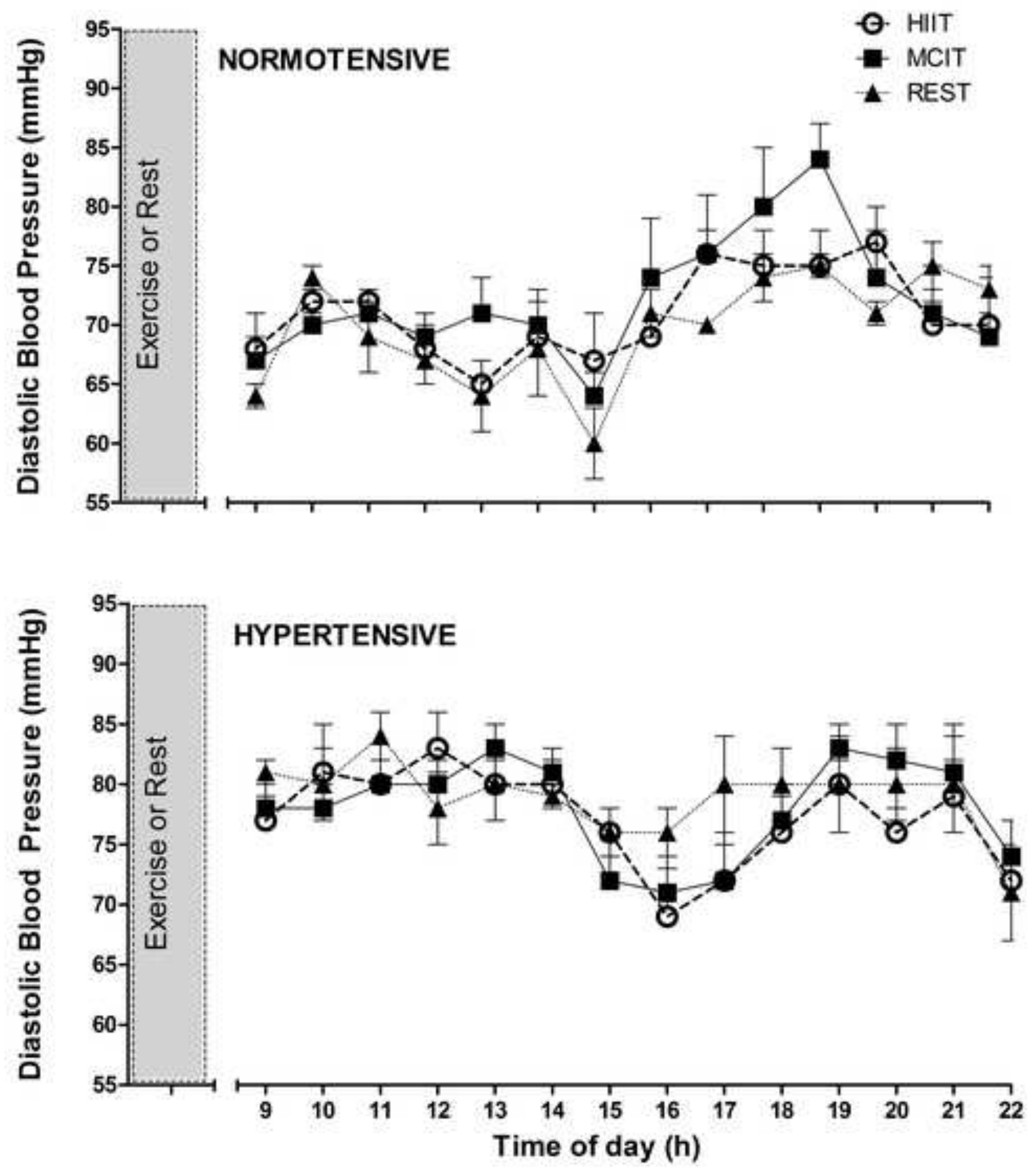
Figure 3
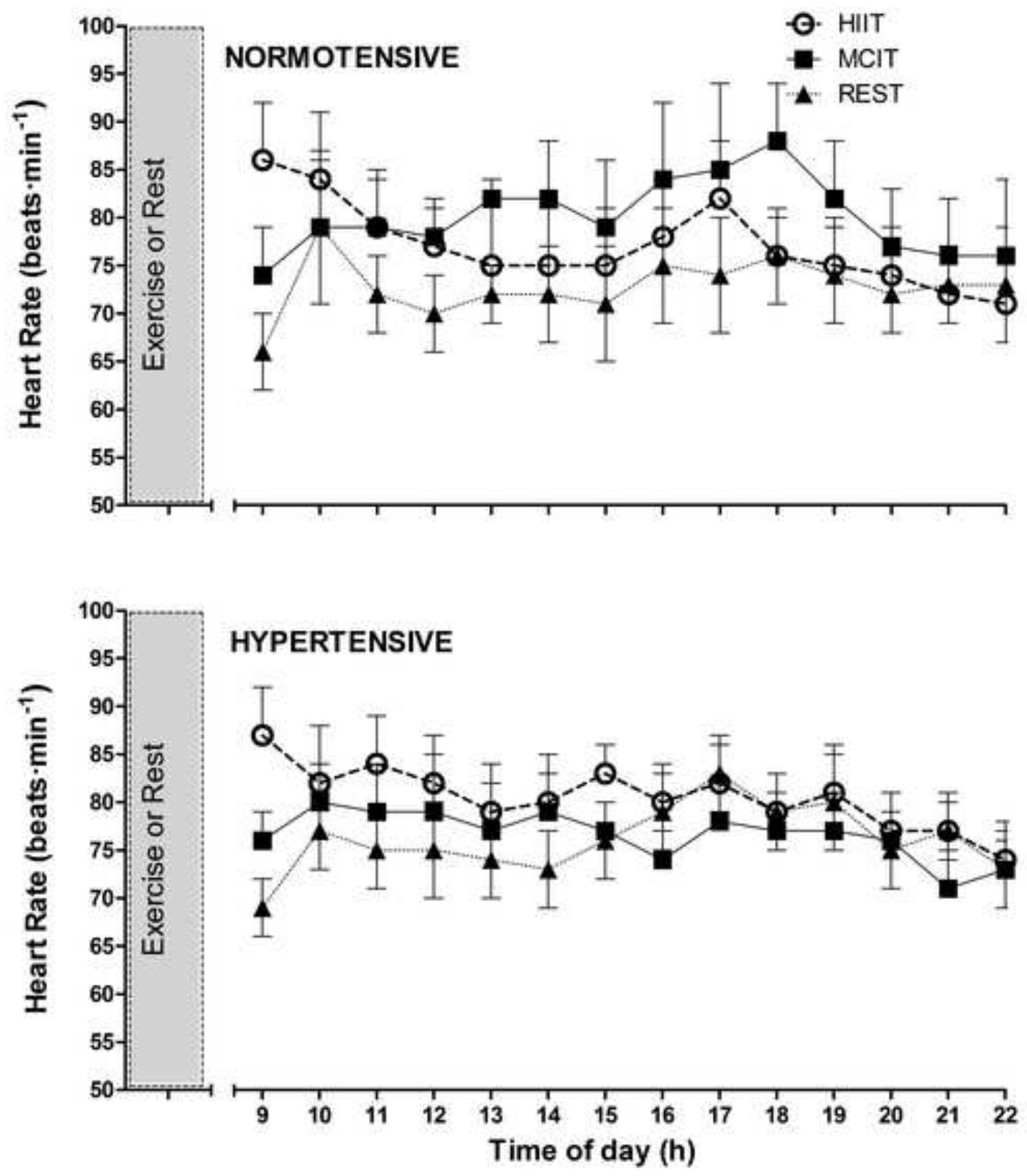
Figure 4
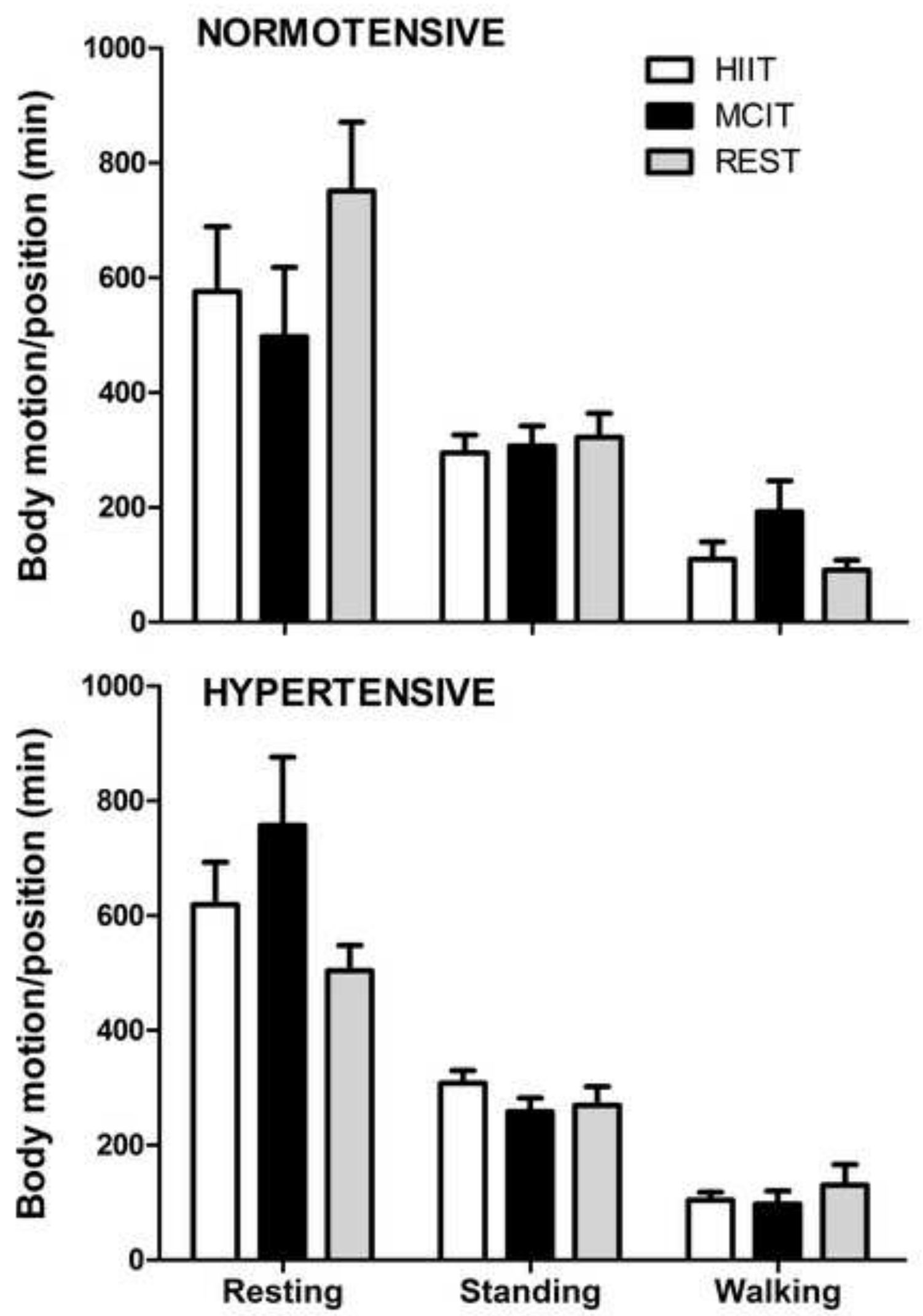
Table 1. Subjects characteristics in the normotensive and hypertensive groups.

\begin{tabular}{|c|c|c|c|}
\hline & Normotensive & Hypertensive & P value \\
\hline $\mathrm{N}$ & 8 & 11 & \\
\hline Gender (men/women) & $(5 / 3)$ & $(8 / 3)$ & \\
\hline Age (years) & $53.3 \pm 9.5$ & $56.5 \pm 6.2$ & 0.396 \\
\hline Weight (kg) & $80.8 \pm 15.3$ & $89.5 \pm 17.6$ & 0.277 \\
\hline $\mathrm{BMI}\left(\mathrm{kg} \cdot \mathrm{m}^{-2}\right)$ & $29.4 \pm 4.1$ & $30.8 \pm 4.7$ & 0.528 \\
\hline Waist Perimeter $(\mathrm{cm})$ & $97 \pm 11$ & $107 \pm 13$ & 0.086 \\
\hline $\mathrm{VO}_{2 \text { peak }}\left(\mathrm{ml} \cdot \mathrm{kg}^{-1} \cdot \mathrm{min}^{-1}\right)$ & $25.4 \pm 6.5$ & $25.2 \pm 4.3$ & 0.781 \\
\hline Systolic Blood Pressure (mmHg) & $116 \pm 7$ & $135 \pm 17 *$ & 0.012 \\
\hline Diastolic Blood Pressure (mmHg) & $65 \pm 7$ & $86 \pm 7 *$ & 0.001 \\
\hline Heart Rate (beats· $\mathrm{min}^{-1}$ ) & $56 \pm 9$ & $61 \pm 7$ & 0.252 \\
\hline
\end{tabular}

Data are presented as mean \pm SD for 19 metabolic syndrome patients, divided into Normotensive and Hypertensive groups. Systolic and diastolic blood pressures measured by ECG gated sphygmomanometer at the brachial artery. * Significantly difference between groups. 